\title{
NATURAL HISTORY OF ONCHOCERCIASIS*
}

\author{
BY
}

\author{
F. H. BUDDEN
}

Overseas Civil Service, Northern Nigeria

Since the first description of ocular onchocerciasis in Africa was published (Hissette, 1931) many records have been made of the ocular lesions (e.g. Bryant, 1935; Hissette, 1938; Toulant and Boithias, 1952a, 1952b, 1954; World Health Organization Regional Conference on Onchocerciasis, 1956). However, no detailed account has been written of the progress of ocular signs and visual acuity in an untreated community, nor has any serious attempt been made to study the prognosis of ocular lesions in onchocerciasis. The need for such assessment is indicated by recent estimates that the disease is the cause of blindness in 10,000 persons in the Northern Territories of the Gold Coast (Waddy, 1956) and 20,000 persons in Northern Nigeria (Budden, 1956) and by the discovery of increasing numbers of Europeans suffering from early ocular lesions acquired in these territories.

Recently an investigation was completed in which a record was made of the changes in visual acuity which occurred during a few years in a village community. In this paper these changes are related to the age, intensity of infection, distribution of microfilariae, and changes in ocular signs. Moreover, an attempt is made to classify the patients seen in Nigeria with a view to providing some guide to prognosis and some indication of which patients require treatment to prevent serious loss of vision.

\section{Progress of Ocular Lesions \\ Method of Investigation}

The village chosen, Bulki, one of the most heavily infected in N. Nigeria, was first examined in September, 1952, when 117 persons were seen. Of these 28 were under 10 years of age and, although thirteen of them had positive skin snips, visual acuity could not always be recorded and a full ocular examination was not always possible. This age group was therefore excluded from the analysis. Bulki was last visited in May, 1956, when of the original series of patients aged 10 years and over, ten were said to be dead, six young women to have married and moved to other villages, and one young man to have moved away. A further three persons were excluded

* Received for publication December 20, 1956. 
because ocular diseases other than onchocerciasis confused the picture. The analysis was limited to the remaining 69 persons.

First Examination (September, 1952).-A skin snip was taken from the left iliac crest and the number of microfilariae per microscope field was recorded by the technique previously described (Budden, 1955). Visual acuity was recorded using an illiterate $E$ test and ability to count fingers at distances up to $6 \mathrm{~m}$. Ocular examination, using focal illumination, loupe, slit lamp, and electric ophthalmoscope, was carried out in a darkened hut.

Second Examination (September, 1953, i.e. 12 months after the first examination).-Only 21 of the 69 persons included in this analysis were re-examined. In these persons the density of microfilariae per $\mathrm{mg}$. of tissue was determined as described by Kershaw, Duke, and Budden (1954). Samples were taken from the skin of the "calf, deltoid, and outer canthus; and also from the conjunctiva.

Third and Final Examination (May, 1956, i.e. 43 months after the first examination).-The method used was the same as at the first visit.

Patient's Age.-This was estimated from the general appearance. The ages quoted in this paper are those at the first visit in 1952.

Changes in Visual Acuity.-Changes of one division (e.g. 6/6 to 6/9, 6/18 to 6/12, or "Hand Movements" to "Perception of Light") were regarded as too small to be reliable and were not recorded as either an improvement or a deterioration.

\section{Findings at Bulki}

(1) Incidence and Density of Infection.-The community as a whole was heavily infected. No person over the age of 19 years had a negative skin snip from the lower half of the body at any visit and only two persons, both female, of the twelve in the 10 to 19 year age group had negative snips. The density of microfilariae in the skin tended to rise with age, i.e. with length of exposure to infection, up to and including the 30 to 39 year age group. Over the age of $\mathbf{4 0}$ years however, the density of microfilariae tended to fall, more particularly in the legs.

(2) Incidence of Ocular Lesions and Reduced Vision at First Examination.(Table 1).- In the 10 to 19 year age group, although microfilariae were present in the anterior chamber of five out of 26 eyes, no loss of visual acuity was found. Visual loss and blindness occurred in the 20 to 29 year age group, and the incidence increased with age until, in persons over the age of 40 years, visual acuity was less than 6/9 in 54 per cent. of eyes, and 29 per cent. of eyes were blind.

(3) Ocular Changes.-During the interval of 43 months between the first and last examination the changes in visual acuity occurred which are recorded in Table I (overleaf). 
CHANGES IN VISUAL ACUIË

\begin{tabular}{|c|c|c|c|c|c|c|c|c|c|}
\hline \multirow{4}{*}{$\begin{array}{c}\text { Age Group } \\
\text { (yrs) }\end{array}$} & \multirow{4}{*}{$\begin{array}{c}\text { Total No. } \\
\text { of Eyes }\end{array}$} & \multicolumn{8}{|c|}{ November, 1952} \\
\hline & & \multicolumn{8}{|c|}{ Eyes with Visual Acuity of: } \\
\hline & & \multicolumn{2}{|c|}{$6 / 6-6 / 9$} & \multicolumn{2}{|c|}{$6 / 12-6 / 24$} & \multicolumn{2}{|c|}{ 6/36-C.F. 4} & \multicolumn{2}{|c|}{ Blin $\stackrel{\bar{\phi}}{\frac{\Phi}{D}}$} \\
\hline & & No. & Percent. & No. & Percent. & No. & Percent. & No. & Pef \\
\hline $\begin{array}{l}10+ \\
20+ \\
30+ \\
40+\end{array}$ & $\begin{array}{l}26 \\
56 \\
28 \\
28\end{array}$ & $\begin{array}{l}26 \\
51 \\
15 \\
13\end{array}$ & $\begin{array}{r}100 \\
.91 \\
54 \\
46\end{array}$ & $\begin{array}{l}0 \\
3 \\
7 \\
6\end{array}$ & $\begin{array}{r}0 \\
5 \\
25 \\
21\end{array}$ & $\begin{array}{l}0 \\
0 \\
4 \\
1\end{array}$ & $\begin{array}{r}0 \\
0 \\
14 \\
4\end{array}$ & $\begin{array}{l}0 \\
2 \\
2 \\
8\end{array}$ & \\
\hline All Ages & 138 & 105 & 76 & 16 & 12 & 5 & 4 & $12^{*}$ & \\
\hline
\end{tabular}

C.F. $4=$ Ability to count fingers at $4 \mathrm{~m}$.

Loss of Vision.-It will be noticed that, although no loss of vision occurred in the 10 to 19 year age group, deterioration in vision occurred in some eyes in all the later age groups, and was most frequent ( 21 per cent. of all eyes) in persons aged 30 to 39 years.

The most severe loss of vision occurred in four eyes which developed glaucoma secondary to iridocyclitis $(1952: 6 / 12,6 / 9,6 / 6,6 / 6 ; 1956$ : perception of light, hand movements, hand movements, hand movements). With the development of other lesions, the deterioration in visual acuity was usually less dramatic, whether loss of vision was considered to be due to anterior segment lesions (1952: counting fingers at $4 \mathrm{~m}$., $6 / 18,6 / 18,6 / 12,6 / 6 ; 1956$ : no perception of light, hand movements, $6 / 60$, counting fingers at $2 \mathrm{~m} ., 6 / 18)$ or choroido-retinal degeneration (1952: counting fingers at $1 \mathrm{~m} ., 6 / 36,6 / 24,6 / 6 ; 1956$ : perception of light, perception of light, counting fingers at $5 \mathrm{~m}$., perception of light).

Improvement in Vision.-This occurred in a small proportion of eyes in the 30 to 39 year age group (vision improved in two out of thirteen eyes: 1952: 6/12, 6/12; 1956: $6 / 6,6 / 6$ ) and in a larger proportion of eyes in the $40+$ age group (vision improved in five out of fifteen eyes: $1952: 6 / 36,6 / 18,6 / 18,6 / 12,6 / 12 ; 1956: 6 / 9$, $6 / 9,6 / 6,6 / 6,6 / 6)$. Improvement in visual acuity was found only in patients with anterior segment lesions and was usually associated with the disappearance of microfilariae from the anterior chamber and the disappearance of the signs of active inflammation, i.e., fluffy corneal opacities and active iridocyclitis).

(4) Association between Intensity of Head Infection and Progress or Regress of Ocular Lesions.-Table II (overleaf) relates the density of microfilariae found in skin snips taken from various parts of the body in September, 1953, to the ocular findings in September, 1952, and May, 1956. It is apparent that relatively heavy infection, particularly in the head region, and persistence of microfilariae in the anterior chamber is usually associated with the progress of anterior segment lesions and loss of visual acuity. Conversely, relatively light infection was associated with improvement in visual acuity or, in persons 
KI IN RELATION TO AGE

\begin{tabular}{|c|c|c|c|c|c|c|c|c|c|c|c|c|}
\hline \multicolumn{7}{|c|}{ May, 1956} & \multicolumn{6}{|c|}{ Difference } \\
\hline \multicolumn{7}{|c|}{ Eyes with Visual Acuity of: } & \multicolumn{6}{|c|}{ Eyes in which Visual Acuity: } \\
\hline $6-6 / 9$ & \multicolumn{2}{|c|}{$6 / 12-6 / 24$} & \multicolumn{2}{|c|}{ 6/36-C.F. 4} & \multicolumn{2}{|c|}{ Blind } & \multicolumn{2}{|c|}{$\begin{array}{c}\text { Remained } \\
\text { Constant }\end{array}$} & \multicolumn{2}{|c|}{ Improved } & \multicolumn{2}{|c|}{ Deteriorated } \\
\hline Percent. & No. & Percent. & No. & Percent. & No. & Percent. & No. & Percent. & No. & Percent. & No. & Percent. \\
\hline $\begin{array}{r}100 \\
87 \\
57 \\
61\end{array}$ & $\begin{array}{l}0 \\
1 \\
2 \\
2\end{array}$ & $\begin{array}{l}0 \\
2 \\
7 \\
7\end{array}$ & $\begin{array}{l}\mathbf{0} \\
\mathbf{0} \\
\mathbf{3} \\
\mathbf{1}\end{array}$ & $\begin{array}{r}0 \\
0 \\
11 \\
4\end{array}$ & $\begin{array}{l}0 \\
6 \\
7 \\
8\end{array}$ & $\begin{array}{r}0 \\
11 \\
25 \\
29\end{array}$ & \begin{tabular}{|l|}
26 \\
50 \\
20 \\
22
\end{tabular} & $\begin{array}{r}100 \\
89 \\
71 \\
79\end{array}$ & $\begin{array}{l}0 \\
0 \\
2 \\
5\end{array}$ & $\begin{array}{r}0 \\
0 \\
7 \\
18\end{array}$ & $\begin{array}{l}0 \\
6 \\
6 \\
1\end{array}$ & $\begin{array}{r}0 \\
11 \\
21 \\
4\end{array}$ \\
\hline 78 & 5 & 4 & 4 & 3 & 21 & 15 & 116 & 84 & 7 & 5 & 13 & 11 \\
\hline
\end{tabular}

figure underestimates the incidence of blindness found at the first visit because several blind persons died before the final visit.

with normal vision at the first examination, with no deterioration. This was particularly obvious when microfilariae were absent from the anterior chamber or, when present at the first visit, disappeared before the final examination.

\section{A Suggested Method of Classifying Onchocercal INFECTIONS IN AFRICA}

Clinical experience in the examination of over 1,600 cases of onchocerciasis, more than 500 of which had ocular lesions, has suggested that patients in whom the microfilariae of $O$. volvulus can be demonstrated may be divided into three types, which, as is shown in the discussion, are believed to be stages in the progress of the disease. To illustrate these three stages and to record their incidence and age distribution, persons were examined in two Northern Nigerian villages: Bulki with a standardized infection rate of 754 , and therefore one of the most heavily infected villages in N. Nigeria, and Mbilla, a typical moderately infected village. Since women tend to be more lightly infected than men, and the development of the three stages takes place more slowly in females, the analysis was confined to men. At each village the analysis was limited to 36 males with the following age distribution:

\footnotetext{
5 to 9 years, five persons 20 to 29 years, nine persons 40 to 49 years, five persons

10 to 19 years, seven persons 30 to 39 years, five persons $50+$ years, five persons.
}

\section{Stage I. Light Infection Regionally Localized}

Microfilariae in relatively small numbers are found in one region of the body, not necessarily the lower limbs; a subcutaneous nodule may be present in the same quarter, and pruritis and papular eruption may also be more intense in the same region. 


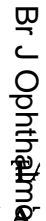

CHANGES IN VISUAL ACUITY AND OCULAR SIGNS IN REL

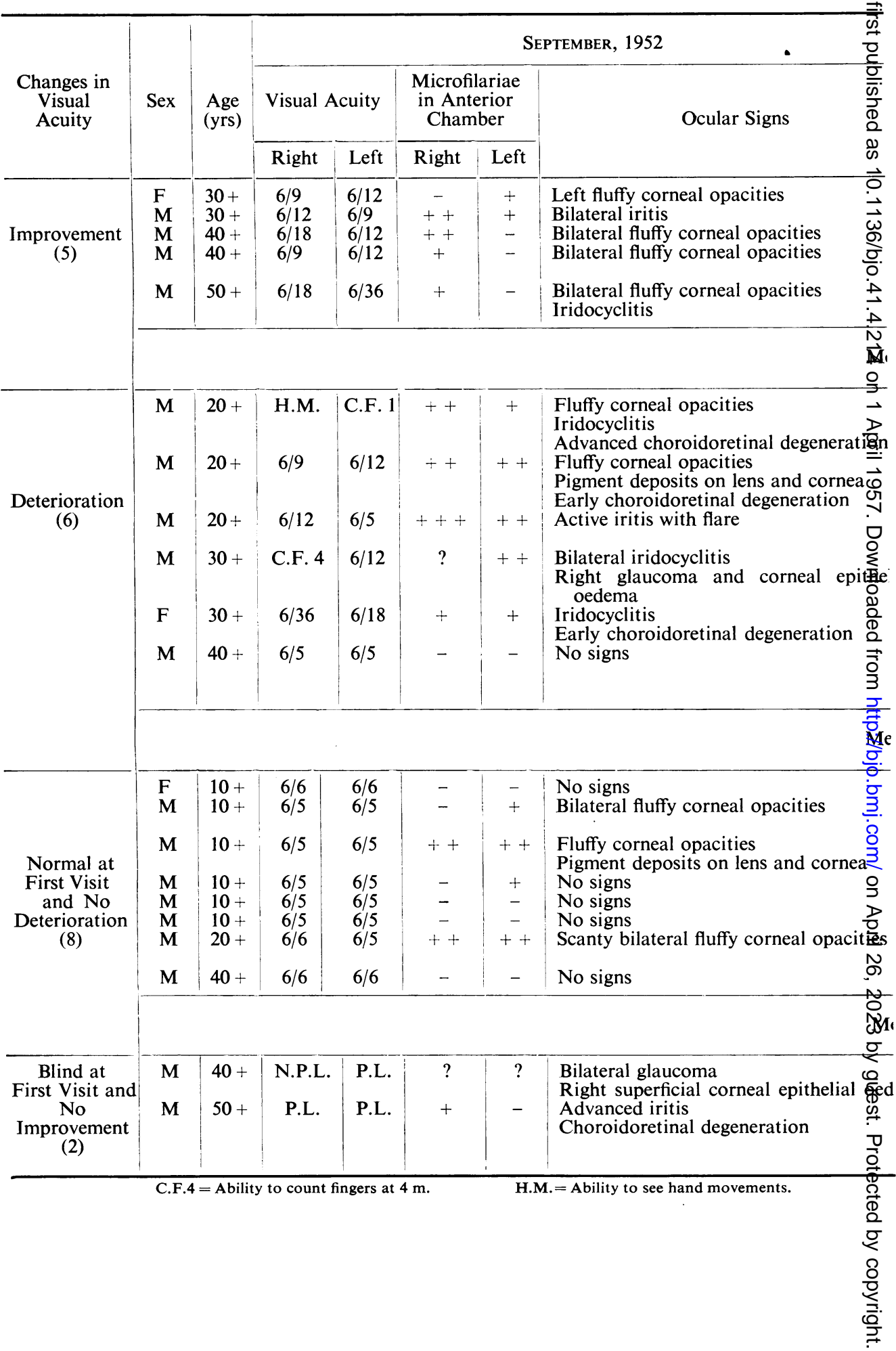


THE DENSITY AND DISTRIBUTION OF MICROFILARIAE

\begin{tabular}{|c|c|c|c|c|c|c|c|c|}
\hline \multicolumn{4}{|c|}{ SEPTEMBER, 1953} & \multicolumn{5}{|c|}{ MAY, 1956} \\
\hline \multicolumn{4}{|c|}{ ensity of Microfilariae per mg. } & \multicolumn{2}{|c|}{ Visual Acuity } & \multicolumn{2}{|c|}{$\begin{array}{l}\text { Microfilariae } \\
\text { in Anterior } \\
\text { Chamber }\end{array}$} & \multirow[t]{2}{*}{ Ocular Signs } \\
\hline llf & Deltoid & $\begin{array}{l}\text { Outer } \\
\text { Canthus }\end{array}$ & $\begin{array}{c}\text { Con- } \\
\text { junctiva }\end{array}$ & Right & Left & Right & Left & \\
\hline $\begin{array}{l}7 \\
0 \\
7 \\
0 \\
0\end{array}$ & $\begin{array}{r}5 \\
18 \\
1 \\
3 \\
\\
60\end{array}$ & $\begin{array}{l}2 \\
1 \\
1 \\
2 \\
2\end{array}$ & $\begin{array}{l}0 \\
0 \\
0 \\
1 \\
\\
4\end{array}$ & $\begin{array}{l}6 / 6 \\
6 / 6 \\
6 / 6 \\
6 / 6 \\
6 / 9\end{array}$ & $\begin{array}{l}6 / 6 \\
6 / 6 \\
6 / 6 \\
6 / 6 \\
6 / 9\end{array}$ & $\begin{array}{l}- \\
- \\
- \\
+ \\
-\end{array}$ & $\begin{array}{l}- \\
- \\
- \\
- \\
-\end{array}$ & $\begin{array}{l}\text { No apparent change } \\
\text { Posterior synechiae } \\
\text { No signs } \\
\text { Bilateral fluffy corneal opacities } \\
\text { Early tongues } \\
\text { Corneal opacities and pigment } \\
\text { deposits less }\end{array}$ \\
\hline 322 & S.D. 22 & $\begin{array}{l}1 \cdot 6 \\
\text { S.D. } 0 \cdot 5\end{array}$ & $\begin{array}{l}1 \cdot 0 \\
\text { S.D. } 1 \cdot 5\end{array}$ & & & & & \\
\hline 0 & 43 & 6 & 18 & P.L. & P.L. & +++ & ++ & No apparent change \\
\hline 0 & 30 & 3 & 3 & H.M. & P.L. & $?$ & $?$ & $\begin{array}{l}\text { Glaucoma } \\
\begin{array}{c}\text { Bilateral } \\
\text { oedema }\end{array}\end{array}$ corneal epithelial \\
\hline 0 & 65 & 6 & 3 & C.F. 2 & $6 / 18$ & + & + & $\begin{array}{l}\text { Posterior synechiae } \\
\text { Choroidoretinal degeneration }\end{array}$ \\
\hline 0 & 55 & 6 & 5 & N.P.L. & $6 / 18$ & $?$ & ++ & $\begin{array}{l}\text { Right corneal degeneration } \\
\text { Left choroidoretinal degenera- } \\
\text { tion }\end{array}$ \\
\hline 7 & 15 & 2 & 8 & P.L. & $6 / 12$ & + & + & $\begin{array}{l}\text { Choroidoretinal degeneration } \\
\text { more advanced }\end{array}$ \\
\hline 0 & 100 & 2 & 3 & $6 / 6$ & $6 / 9$ & + & + & $\begin{array}{l}\text { Fluffy opacities } \\
\text { Early left choroidoretinal de- } \\
\text { generation }\end{array}$ \\
\hline .62 & S.D. 27 & S.D. $1 \cdot 9$ & $\begin{array}{l}6 \cdot 6 \\
\text { S.D. } 5 \cdot 4\end{array}$ & & & & & \\
\hline $\begin{array}{l}0 \\
9\end{array}$ & $\begin{array}{l}1 \\
7\end{array}$ & $\begin{array}{l}1 \\
2\end{array}$ & $\begin{array}{l}0 \\
0\end{array}$ & $\begin{array}{l}6 / 6 \\
6 / 6\end{array}$ & $\begin{array}{l}6 / 6 \\
6 / 6\end{array}$ & - & + & $\begin{array}{l}\text { No signs } \\
\text { Bilateral fluffy corneal opacities } \\
\text { more numerous }\end{array}$ \\
\hline 6 & 5 & 2 & 4 & $6 / 6$ & $6 / 6$ & ++ & ++ & $\begin{array}{l}\text { No change except tongues of } \\
\text { corneal opacity developed }\end{array}$ \\
\hline 0 & 12 & 1 & 1 & $6 / 5$ & $6 / 5$ & - & - & No signs \\
\hline 5 & 5 & 1 & 0 & $6 / 5$ & $6 / 5$ & - & + & No signs \\
\hline 8 & 4 & 0 & 0 & $6 / 5$ & $6 / 5$ & - & - & Bilateral fluffy corneal opacities \\
\hline $\mathbf{0}$ & 2 & 1 & 0 & $6 / 6$ & $6 / 5$ & - & - & $\begin{array}{l}\text { Scanty fluffy corneal opacities } \\
\text { right eye only }\end{array}$ \\
\hline 0 & 5 & 1 & 1 & $6 / 6$ & $6 / 6$ & - & - & No signs \\
\hline 15 & $\begin{array}{l}5 \cdot 1 \\
\text { S.D. } 3 \cdot 1\end{array}$ & S.D. $1 \cdot 7$ & $\begin{array}{l}0 \cdot 7 \\
\text { S.D. } 1 \cdot 3\end{array}$ & & & & & \\
\hline 0 & 110 & 10 & 2 & $\begin{array}{l}\text { N.P.L. } \\
\text { N.P.L. }\end{array}$ & $\begin{array}{l}\text { N.P.L. } \\
\text { N.P.L. }\end{array}$ & - & $?$ & $\begin{array}{l}\text { Bilateral glaucoma } \\
\text { Bilateral superficial corneal } \\
\text { epithelial oedema } \\
\text { No apparent change }\end{array}$ \\
\hline
\end{tabular}


Ocular Lesions.-These are uncommon. Microfilariae only occur in the head region in a small proportion of persons, and even if the organisms do invade the anterior segment of the eye, their numbers are small and ocular lesions may or may not occur. Symptoms when present are mild conjunctival irritation and photophobia. The signs are slight injection and oedema of the conjunctiva, slightly increased lacrimation, and moderate numbers of fluffy corneal opacities. The opacities lie in the superficial layers of the substantia propria and are usually situated near the limbus in the interpalpebral area. These corneal lesions appear to start as a fluffy longitudinal opacity around a dead microfilaria, but when fully developed they are disc-shaped and about $0.5 \mathrm{~mm}$. in diameter. They were well described at the World Health Organization Conference on African Onchocerciasis in October, 1954, by Dr. A. J. Boase (Specialist Ophthalmologist, Uganda) as having the appearance of cracked ice. They slowly resolve over a period of about 3 months after the disappearance of microfilariae from the eye. The term "fluffy" is preferred to the term "nummular" (Ridley, 1945), to distinguish the lesions characteristic of active ocular onchocerciases from the homogeneous disc-shaped corneal opacities commonly seen in Nigeria in persons who have never been exposed to onchocerciasis.

Very fine brown pigment deposits on the posterior surface of the cornea and anterior surface of the lens may be seen in the heavier African infections. No other ocular lesions were seen at this stage. Visual acuity is usually normal.

\section{Stage II. Generalized Infection}

The intensity of infection is heavy and generalized. The concentration of microfilariae is highest in the lower limbs, but the organisms are also present in the head region and may invade the eyes, where they are seen in conjunctival snips, motile in the anterior chamber, adherent to the posterior surface of the cornea, or lying immobile in the substantia propria. Lichenification, which is most marked on the skin of the lower limbs, also appears on the upper trunk, upper limbs, and head. Nodules tend to be present in larger numbers than in Stage $\mathrm{I}$.

Ocular Lesions. - When invasion of the anterior segment of the eye is small the reaction is the same as in Stage $I$. When invasion is heavy, patients complain of ocular pain, photophobia, and blurred vision. Slight oedema of the lids may occur. The conjunctiva is slightly oedematous and slightly injected, particularly near the limbus, and mild ciliary injection may be present. Small inflammatory swellings resembling phlyctens may develop in the conjunctiva.

The cornea contains fluffy opacities similar to those seen in Stage I, but they may be present in larger numbers and be scattered over the whole interpalpebral area. What appear to be microfilariae may be seen as opaque, motionless, corrugated threads in the substantia propria-a motile microfilaria such as described by Ridley (1945) has not been seen. At a later stage in heavy infections the fluffy opacities appear to coalesce, forming an area of superficial corneal opacity, often with some pigmentation, spreading into the cornea like tongues at 4 o'clock and 8 o'clock. The opacity spreads around the cornea adjoining the 
lower half of the limbus and eventually invades the pupillary area. Degenerative changes may occur in this opaque area.

Fine pigment deposits occur on the posterior surface of the cornea and anterior surface of the lens. They tend to be more numerous than in Stage I and may coalesce to form larger irregular pigment deposits. Posterior synechiae may develop and secondary glaucoma is not uncommon. Signs of active iridocyclitis, i.e. true keratitis punctata, flare, and cells in the anterior chamber are rarely seen and then only in heavily infected patients. The pear-shaped pupil, drawn down towards an opaque mass at the base of the anterior chamber has been seen only rarely (nine cases).

After long-standing intense ocular infection the iris appears smooth, atrophic, and slightly depigmented. The lens capsule may exfoliate. True secondary cataract, as distinct from coincident senile cataract, is uncommon and only occurs in very heavy infections.

Choroido-retinal degeneration may be seen in long-standing infections of this type. The most usual changes are a widespread gross tigroid appearance, presumably due to thinning of the retina, and aggregations of superficial retinal pigment which may be of very varied size and shape. The retinal blood vessels are often narrowed and may be sheathed for up to two disc diameters beyond the disc, and the nervehead atrophies. Large patches of choroidal sclerosis may be seen in advanced cases. These changes have been described in detail by Hissette (1931 and 1938), Bryant (1935), Ridley (1945), and Toulant and Boithias (1954),

Active papillitis was seen in a small number of patients.

\section{Stage III. Regression}

The concentration of microfilariae in the skin is less than in Stage II, and if microfilariae are present in the head region they occur only in small numbers unsupported by a high concentration in the lower part of the body. Lichenification of the skin tends to be replaced by atrophic changes, i.e. "a crushed tissue paper" appearance over most of the body, together with, in some previously heavy infections, smooth atrophic skin with mottled white patches overlying the shins. Nodules tend to be present in still larger numbers than in Stage II.

Ocular Lesions.-Microfilariae are not seen in the anterior segment of the eye and no active inflammatory reaction occurs. Opaque corneal infiltration, pigment deposits, posterior synechiae, and glaucoma produced by previous inflammation are present in many eyes. Choroido-retinal degeneration and optic atrophy also occur.

In addition to these three stages in which microfilariae are found, there is an incubation period lasting about 15 to 18 months before microfilariae are demonstrable in the skin or eye. Moreover, a late stage of burnt-out infection sometimes occurs in elderly persons in whom typical dermal and sometimes ocular lesions are present, but in whom microfilariae are not found. 
Distribution of the Different Stages of Onchocercal Infection and of Ocular Lesions amongst Persons living in Areas of Heavy, Moderate, and Light Endemicity and amongst Persons exposed to Occasional Infection only

(1) Heavy Endemic Areas (Standardized infection rate, as determined by a single skin snip from the left iliac crest, more than 501 per 1,000 persons of all ages).-The intensity of infection in individual persons is usually heavy. Stage I occurs early in life and most persons are suffering from Stage II infection. Stage III is uncommon but may be seen in elderly persons. The data for Bulki, one of the most heavily infected villages in N. Nigeria, are given in the Figure (opposite).

Massive and prolonged invasion of the anterior segment of the eye by microfilariae in Stage II leads to severe lesions, i.e. opaque corneal infiltration and iridocyclitis. This is the major cause of visual loss, though choroidoretinal degeneration is also common (Budden, 1955).

(2) Moderate Endemic Areas (Standàrdized infection rate 251-500 per 1,000 persons of all ages). - The intensity of infection in individual persons is usually moderate. Stage I infection appears in the second and third decades of life, Stage II is most common in the fourth decade, and Stage III in the fifth and sixth decades. Data for Mbilla, a typical village of this type, are given in the Figure (opposite).

The major cause of reduced vision is choroido-retinal degeneration, but as the anterior segment of the eye is invaded by moderate numbers of microfilariae in Stage II infections the resultant iridocyclitis is almost as important a cause of visual loss (Budden, 1955).

(3) Light Endemic Areas (Standardized infection rate 0-250 per 1,000 persons of all ages).-The intensity of infection in individual persons is usually light. Stage I infection is seen in all age groups, but Stage III predominates in persons over the age of 50 years. Stage II infection is uncommon and in some of the most lightly infected villages has never been seen. When it occurs the number of microfilariae entering the eye is so small that iridocyclitis, the only permanent lesion of the anterior segment, is infrequent.

Visual loss is uncommon and is usually due to choroido-retinal degeneration in the later years of life (Budden, 1955).

(4) Persons exposed to Occasional Infection (Expatriates and Africans normally living in non-endemic areas).-Stage I infection is common. A European with Stage I infection involving the eyes was described by Ridley and Anderson (1950), and two other European patients, probably at this stage of infection but with no eye involvement, were described by Chartres (1955).

Microfilariae invade the anterior segment in small numbers in Stage I, producing a few transient fluffy opacities and sometimes, in Africans, 


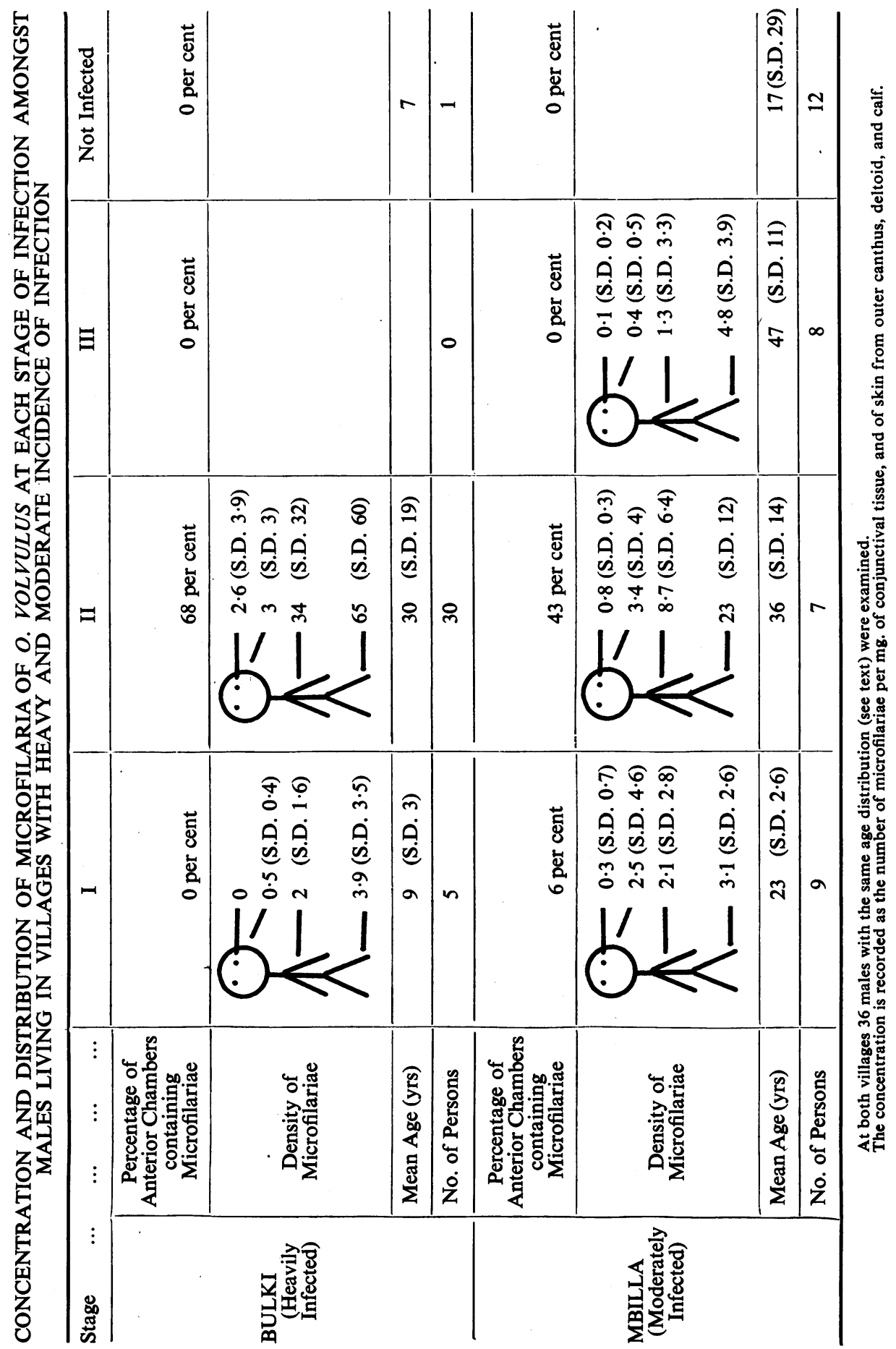


deposits of fine pigment on the posterior surface of the cornea and anterior surface of the lens. No active iridocyclitis, opaque corneal infiltration, or choroido-retinal lesion has been seen by the author in this type of patient.

\section{DISCUSSION}

\section{(1) Classification of ONChocercal Infection}

It is believed that the types of onchocercal infection described are in fact stages in the progress of the disease in a person living in an endemic area and therefore, presumably, exposed to repeated infection up to the time of examination. This is suggested by the fact that, at both villages investigated, the mean age of the patients rises progressively from Stage I to Stage III (Figure). Moreover, at Bulki, where it was possible to re-examine patients after an interval, some patients who were at one stage at the first visit had progressed to the next stage before the final visit.

The occurrence of Stage II depends on the building up of a heavy parasitic infestation in the definitive host; it has not been seen in persons visiting endemic areas, and it is uncommon in natives of lightly endemic areas.

\section{(2) Pathogenesis of Ocular Lesions}

Ocular lesions are related to the stage and intensity of infection:

Anterior Segment Lesions.-Previous investigation showed that the development of anterior segment lesions (keratitis involving the pupillary area and iridocyclitis) was associated with intense infection and the invasion of the anterior segment of the eye by microfilariae (Budden, 1955). Bulki is a heavily infected community and lesions of the anterior segment therefore dominate the ocular picture. The present findings clearly demonstrate that the progress of these lesions is associated with the presence of microfilariae in the anterior chamber supported by a heavy concentration of microfilariae in the head region. They also show that these lesions do not develop, or that they regress if present at an early stage, when microfilarae in the anterior chamber are absent or few, and are only supported by a low concentration of microfilariae in the head region.

It is apparent not only that these lesions are dependent on the invasion of the anterior segment by microfilariae but that the type of lesion developing depends on the intensity of this invasion. Microfilariae may invade the anterior chamber without signs developing; fluffy corneal opacities, pigment deposits on the posterior surface of the cornea and anterior surface of the lens, posterior synechiae and opaque corneal infiltration tend to occur in that sequence as the intensity of microfilariae in the anterior chamber rises.

There are two opportunities for microfilariae to invade the anterior segment of the eye and produce these lesions-in Stages I and II. Thus the fluffy corneal opacities, and in Africans pigment deposits, which develop in Stage I are liable to occur in expatriates or in Africans visiting endemic areas, as well as in natives of endemic areas. In the latter group this stage tends to be seen at an earlier age as the endemicity rises. The more serious lesions, leading to a permanent loss of vision, appear to develop only as a result of Stage II infection. In natives of 
lightly infected areas this invasion of the anterior segment is rare and the intensity of invasion is low; thus pigment deposits and posterior synechiae are the only permanent lesions to develop. In natives of heavily endemic areas, on the other hand, Stage II infection develops at a relatively early age and the intensity of microfilariae in the anterior segment at this stage is so heavy that all types of anterior segment lesion are liable to occur.

Posterior Segment Lesions.-Choroido-retinal lesions have not been seen by the author in very lightly infected persons (e.g. in Europeans who have only been exposed intermittently). Choroido-retinal lesions occur in natives of all endemic areas including the most lightly infected villages where Stage II has never been seen. The incidence of these lesions increases and the average age of onset falls as the intensity of infection in the community rises. There is still some doubt how onchocercal infection produces these lesions, although it has been suggested (Budden, 1955) that they are unlikely to be due to the invasion of the eye by microfilariae along the same route as that which causes anterior segment lesions and that they may possibly result from a circulating toxin.

In conclusion, I would stress that our present knowledge is fragmentary. For instance, it is not known why microfilariae concentrate in the lower part of the body in Stage II, although it would appear that this distribution assists the uptake of microfilariae by $S$. damnosum, which in Nigeria bite almost exclusively on the legs (Crosskey, 1955). It is not known why, at a later stage in the disease, microfilariae are always found in the head region (Stage II), although this spread appears to be related to an increase in the concentration of microfilariae in the body as a whole. It is not known why the concentration of microfilariae in the skin and in the eyes falls in the later stages of the disease (Stage III) whilst the patient is still presumably exposed to infection, although this may be related to a different mode of life in old age, increased resistance on the part of the host, or anatomical changes in the skin excited by the prolonged presence of microfilariae (see Jamison, Kershaw, Duke, and Fejer, 1955). Although it has been possible to study the progress of the disease in natives of endemic areas, I have little information about the progress of infection acquired during exposure for a limited period. However, it seems likely that, although mild onchocerciasis has only recently been diagnosed amongst Europeans serving in West Africa, it previously existed and that, although no treatment was given, the consequences were not sufficiently serious to attract attention. Although these gaps in our knowledge remain, the study of the incidence of the ocular lesions in different communities and the relationship of these lesions to the concentration and distribution of microfilariae in the body as a whole has thrown some light on the natural history of ocular onchocerciasis, and provided some guide to prognosis and treatment.

\section{(3) Prognosis}

Consideration of the stage and intensity of infection together with age and 15 
likelihood of re-infection provides a basis on which an assessment can be made of the risk of ocular lesions developing, or of the progress or regress to be expected in existing lesions.

Anterior Segment Lesions. - Slight conjunctival irritation, conjunctival inflammation, and fluffy corneal opacities may develop in any person in whom microfilariae enter the anterior part of the eye even in small numbers, i.e. in Stage I involving the head region or in light Stage II infection. However, these lesions do not always follow invasion of the eye by microfilariae and if they develop they resolve later. No permanent loss of vision is to be expected unless a more heavy invasion occurs. Heavy invasion of the anterior segment by microfilariae is liable to occur at Stage II in natives of moderately or heavily endemic areas, and the risk can be assessed in the individual from the concentration of microfilariae in the skin and anterior chamber. The severity of the lesions to be expected increases with the concentration of microfilariae in the body particularly in the head region.

Posterior Segment Lesions.-The risk of developing these lesions increases with the intensity and duration of infection in the individual. No improvement in visual acuity or visual fields can be expected except in acute papillitis.

In the past, failure to appreciate the widely different ocular prognosis in different stages and intensities of infection has led to considerable confusion and unnecessary anxiety, particularly among laymen. There is an unfortunate tendency for them to use the term "river blindness" as synonymous with onchocerciasis in infections which would be more accurately described by some such term as "river itch".

\section{(4) THERAPY}

Consideration of the way in which the stage and intensity of infection affect ocular prognosis helps to determine what treatment, if any, is indicated to protect the eyes.

Individual Patients.-Before embarking on treatment with filaricides in an attempt to prevent visual loss, the risk of such loss should be balanced against the discomfort and risk of treatment. For instance, although treatment with filaricides may be indicated in Stage I for other reasons, it is doubtful whether it is ever required at this stage to prevent loss of vision; at the other extreme, treatment is urgently required in heavy Stage III infections.

Mass Treatment.-In villages such as Bulki where 27 per cent. of the population over 30 years of age is blind one may be justified in attempting heroic measures in an attempt to control the progress of the disease. In the present state of our knowledge it is probably advisable to limit treatment to the younger age groups since it is here that prevention will be most effective and reactions to the destruction of the filariae least severe. 


\section{SUMMARY}

The changes occurring in the eyes of a village community exposed to heavy endemic onchocerciasis over a period of 43 months are recorded.

Although visual deterioration was common, spontaneous improvement in ocular lesions and visual acuity occurred in a small proportion of persons.

The ocular changes are related to the concentration and distribution of microfilariae in the body.

Three stages in the progress of human infection with onchocerciasis which have been observed in Nigeria are described and the ocular lesions liable to occur at each stage are noted.

The prognosis of ocular onchocerciasis and its application to therapy are discussed in relation to the stage and intensity of infection.

I wish to thank Dr. D. J. M. Mackenzie, O.B.E., Director of Medical Services, Northern Region, Nigeria, for permission to publish this paper; Dr. M. P. Hutchinson, Senior Research Epidemiologist, West African Institute for Trypanosomiasis Research, for reading and criticizing the draft; Dr. W. E. Kershaw and Dr. B. O. L. Duke for allowing me to use some of their figures for density of microfilariae in skin snips at Bulki; and Mr. P. Henry, S.R.N., and the junior staff of the Medical Field Units for assistance in carrying out the surveys.

\section{REFERENCES}

Bryant, J. (1935). Trans. roy. Soc. trop. Med. Hyg., 28, 523.

BuDDEN, F. H. (1955). British Journal of Ophthalmology, 39, 321. (1956). Trans. roy. Soc. trop. Med. Hyg., 50, 366.

Chartres, J. C. (1955). West Afr. med. J., n.s. 4, 130.

Crosskey, R. W. (1955). Ann. trop. Med. Parasit., 49, 142.

HissetTe, J. (1931). Ann. Soc. belge Méd. trop., 11, 45. (1938). Amer. J. trop. Med., 18, Suppl., p. 58.

Jamison, D. G., Kershaw, W. E., Duke, B. O. L., and Fejer, E. A., (1955). Ann. trop. Med. Parasit., 49, 227.

KershaW, W. E., Duke, B. O. L., and Budden, F. H. (1954). Brit. med. J., $2,724$.

RIDLEY, H. (1945). “ Ocular Onchocerciasis". British Journal of Ophthalmology, Monograph Suppl. $X$. Pulman, London. and ANDERSON, J. (1950). British Journal of Ophthalmology, 34, 688.

Toulant, P., and Borthias, R. (1952a). Bull. Acad. nat. Méd. (Paris), 136, 378. (1952b). Bull. Soc. Path. exot., 45, 811.

WADDY, B. B. (1956). Trans. roy. Soc. trop. Med. Hyg., 50, 328.

WORLD Health ORganisation (1956). Report of Conference on African Onchocerciasis, (mimeographed) Geneva. 